\title{
Infrastructure Projects for Green Cities between Implementation Challenges and Efficiency Indicators
}

\author{
Ahmed M. Selim ${ }^{1, *}$, Doha M. Saeed ${ }^{2}$ \\ ${ }^{1}$ Department of Architecture, Modern Academy for Engineering and Technology, Cairo, Egypt \\ ${ }^{2}$ Faculty of Engineering and Technology, Badr University in Cairo (BUC), Egypt
}

Received December 7, 2020; Revised January 28, 2021; Accepted February 24, 2021

\begin{abstract}
Cite This Paper in the following Citation Styles
(a): [1] Ahmed M. Selim, Doha M. Saeed, "Infrastructure Projects for Green Cities between Implementation Challenges and Efficiency Indicators," Civil Engineering and Architecture, Vol. 9, No. 2, pp. 347 - 356, 2021. DOI: 10.13189/cea.2021.090208.
\end{abstract}

(b): Ahmed M. Selim, Doha M. Saeed (2021). Infrastructure Projects for Green Cities between Implementation Challenges and Efficiency Indicators. Civil Engineering and Architecture, 9(2), 347 - $356 . \quad$ DOI: 10.13189/cea.2021.090208.

Copyright $\odot 2021$ by authors, all rights reserved. Authors agree that this article remains permanently open access under the terms of the Creative Commons Attribution License 4.0 International License

\begin{abstract}
The world's population will be 9.2 billion in 2050 , which is 2.2 billion more than today, with most of the increase in Africa, the Middle East, and South Asia. That will negatively affect the availability of arable land, infrastructure, and environmental performance of cities, furthermore, achieving sustainability pillars (environmental, economic, social) becomes mandatory for all countries after signing in the recommendation of the 2015 UN Summit, many initiatives and concepts were adopted to face these challenges and accomplish sustainable development. The green cities concept (GCC) and its strategies are considered an optimum approach to achieve sustainable development objectives and overcome these challenges, by enhancing performance for the existing infrastructure, reducing natural resource consumption, decreasing $\mathrm{CO}_{2}$ emission, and engaging citizens in decision-making. On another hand, infrastructure projects are vital for achieving (GCC) concept because it reflects the progress and economic performance of countries. This study discusses the green cities, conventional and green infrastructure challenges, then presents Public-Private Partnership (PPPs) as a tool for implementing and overcoming its challenges from the green economy and green contracts perspectives. In addition, concluding an Operational Framework for implementing infrastructure projects by (PPPs) which determines the main phases in (PPPs), allocates the most important strategies for each phase, and indicates the main internal stockholders who share in decision-making. Finally, the study assigns (53) efficiency indicators and
\end{abstract}

obtains a weight for each indicator by identifying the Relative Importance Index through an online questionnaire evaluated by (15) experts to track the achievement of the operational framework.

Keywords Infrastructure Projects, Green Cities, Implementation Challenges, Efficiency Indictors

\section{Introduction}

Regarding the 2015 UN summit under title (Transforming our world: Sustainable Development plan 2030) recommendations, which adapted 17 goals [1], the newly agenda concentrates on issues related to sustainable urbanization within specific a goal as: (Goal 11) "make cities and human settlements safe, inclusive, resilient and sustainable and strengthen implementation of the international partnership (Goal 17). As well, a number of other goals are related to this issue, those on clean water and sanitation (Goal 6), and affordable and clean energy (goal 7). In fact, most of the countries adopted different initiatives to achieve this agenda. Green Cities Concept (GCC) and its strategies are considered an optimum approach to achieve sustainable development objectives and overcome these challenges, where, The (GCC) not only affects the urban development growth but also the economic and social growth of the cities as by its aspects which aim to achieve a reduction in natural resources and 
energy consumption, decrease $\mathrm{CO} 2$ emission, promote infrastructure projects, in addition, enhance social equity, encourage civil society participation in decision making. Also, it opens the way for the development of other concepts such as green infrastructure, and green economy. From another hand, and to achieve (GCC) concept, infrastructure development becomes certain because it reflects directly the overall sustainable development pillars, however, various challenges are associated with implementing this approach, the most important challenges related to the development and establishment of infrastructure projects are funding and technology. The governments recognize that gate to bridge these challenges is the partnership with the private sector as a smart substitute to develop and expand the resource of infrastructural facilities through the green Public-Private Partnership (PPPs) approach. The study presents an Operational Framework for implementing infrastructure projects by (PPPs) which determines the main phases in (PPPs), allocates the most important strategies for each phase, and indicates the main internal stockholders who share in decision making. Finally, the study assigns (53) efficiency indicators and obtains a weight for each indicator by identifying the Relative Importance Index through an online questionnaire evaluated by (15) experts to track the achievement of the operational framework.

\section{Research Objectives and Methodology}

As a result of the rapid growth of the world population and to achieve the (17) goals of the UN summit ( transforming our world), the world governments adopted many concepts and strategies to achieve sustainable development, green cities concept is one of the initiatives which could participate in promoting the sustainable development pillars.

\subsection{Research Objectives}

This study is carried out to discuss the green cities concept, starting from its definitions, implementation strategies, and challenges, also, suggest operational framework and efficiency indicators to improve the effectiveness of executing infrastructure projects and measure its performance, whether conventional or green through (PPPs).

\subsection{Research Methodology}

The research focuses on three axes, (A)-The first axis is a literature review by: identifying green cities, introducing infrastructure implementation challenges for green cities using the inductive method. (B)-The second axis is suggesting an operational framework for infrastructure implementation; it was concluded from the literature review analysis using the analytical method. (C)-The third axis is collecting the data: a quantitative study based on a surveying technique (online questionnaire) prepared by the authors, the study summarized (53) indicators, classified on (38) indicators related to the green city concept, and (15) related to the potential risks. After selecting the indicators, an online questionnaire is prepared and evaluated by (30) experts specialized in environmental planning and project management as illustrated in Table(1) to obtain a weight for each indicator by identifying the Relative Importance Index.

Table 2. Participant of online questionnaire

\begin{tabular}{c|c}
\hline Participants & Number \\
\hline Academic stuff & 6 \\
\hline $\begin{array}{c}\text { Environmental planning } \\
\text { professional }\end{array}$ & 9 \\
\hline NOGs & 4 \\
\hline Regional authorities & 3 \\
\hline Central authorities & 3 \\
\hline Project manager (developers) & 30 \\
\hline Total &
\end{tabular}

Source: by the author

\section{Literature Review}

\subsection{Green Cites}

There are many initiatives for the green cities concept (GCC) mentioned in the literature reviews, most of them concentrate on the environmental treatments to reduce the environmental impact on the urban spaces[2], nowadays another definition is associated with green " green means different things to different peoples"[3]. In this study, we adopt a comprehensive definition for green cities as "cities that have already achieved or are going toward environmental, social, and economical sustainable development in all of its aspects" [4] by enhancing performance for infrastructure, reducing costs and resource consumption, and engaging citizens and civil society in decision making. On the other hand, the implementation of (GCC) requires strategies to carryout, which must reflect the three pillars of sustainability, therefore, the most important strategies are:

- Strategies related to the environmental pillar as: (a) energy consumption and co2 emission, (b) water conservation, (c) waste management, (d) air quality, (e) land use, green infrastructure, and (f) public transport [5,6].

- Strategies related to the economical pillar as: (a) green economic, (b) green contracts approach, (c) infrastructure risk management, and (d) private sector participation. 
- Strategies related to the social pillar as: (a) governance, and (b) citizens health,

In fact, to foster such strategies, four principles must be applied, the first is (Reuse, Reduce, Recycle, and Recovery) or (4R) for resources[7], the second is information, communication, and technology (ICT) approach for infrastructure development [8], the third is science, technology, and innovation (STI) instead of value for money (VFM) in evaluation the projects especially infrastructure projects[9], the fourth is "use less and do more" [10].

\subsection{Infrastructure for Green Cities}

Indeed, Infrastructure projects are considered the main approach to achieve sustainable development [11], and the indicators related to infrastructure growth reflect directly the progress and economic performance of countries. However, there is no unique definition of infrastructure across urban or economic studies, because each study defines and classifies infrastructure according to the nature of its effect, most of the literature reviews especially in urban studies define infrastructure as the basic public capital which provides essential needs, and services or solves problems for specific society[12], regarding this definition infrastructure can be classified: economic infrastructure, directly promotes productive activities like (water network, sewer network, roads, railways, airports,.....), and social infrastructure, directly improves the social comfort and to enhance the economic productivity like ( schools, hospitals, green areas, planet of waste disposal,...) [13]. In parallel, and to achieve sustainability pillars, environmental infrastructure terminology was emerged as a sub-dimension under social infrastructure classification in 2006 by the Italian national institute of statistics (ISTAT)[14], and it includes (waste disposal, green areas, water purification planet).
Furthermore, and with the rapid growth of communities and to reduce the accelerated consumption of open land (parks and green area), a new term was introduced as a strategic approach for land conservation for green cities, this term is green infrastructure.

Green infrastructure benefits have expanded during the last decade to include $[\mathbf{1 5 , 1 6 , 1 7 ]}$ :

- link parks and other green spaces for people benefits, - promote smart conservation and smart growth,

- protect and restore naturally functioning ecosystems,

- support a diversity of economic, ecological, and social functions,

- provide cleaner air and improving water quality, therefore, improve health,

- promote collaborative partnerships,

- reduce combined sewer overflow (CSO),

- flood mitigation,

- reuse wastewater,

- reduce energy consumption,

- link natural areas to counter fragmentation and preserve biodiversity.

Planning of conventional or green infrastructure projects requires the following six strategies in a way of that are: proactive not reactive; multifunctional not single purpose; systematic not haphazard; multi-jurisdictional not single jurisdictional; and multiple scales not single scale [18].

\subsection{Green Cities and Infrastructure Challenges}

In spite of the numerous benefits of conventional and green infrastructure for communities growth and welfare, various challenges are associated with implementing this approach, the key aspects of these challenges for both infrastructures are illustrated in Table (2) and Table (3), as well as, the actions to deal with and overcome these challenges. 
Table 2. Conventional Infrastructure Challenges

\begin{tabular}{c|ll}
\hline Challenge & & \multicolumn{1}{c}{ Actions } \\
\hline \multirow{3}{*}{ Population Growth } & $\bullet$ & Determine and describe the actual needs, \\
& $\bullet$ & $\begin{array}{l}\text { Determine priorities for the community, } \\
\text { Accelerate the urban infrastructure planning documents and implementation to meet the } \\
\end{array}$ \\
expected population growth.
\end{tabular}

Source: Summarized from $[19,20,21] \&$ by the author

Table 3. Green Infrastructure Challenges

\begin{tabular}{c|ll}
\hline Challenge & & \multicolumn{1}{c}{ Actions } \\
\hline \multirow{4}{*}{ Gap between Theory and Practice } & $\bullet$ & Adaptation of green infrastructure concept in local conditions, \\
& $\bullet$ & Provide smart governance model, \\
& $\bullet$ & Take the resident perspectives into consideration, \\
& $\bullet$ & Encourage local initiatives for this concept, \\
& $\bullet$ & Decline social inequities. \\
\hline \multirow{4}{*}{ High Risks in Implementation } & $\bullet$ & Address acceptable quality level (AQL), \\
& $\bullet$ & Provide long- term maintenance plan, \\
& $\bullet$ & Use environmental mechanisms and tools in evaluation, \\
& $\bullet$ & Transfer knowledge for the private sector, \\
& $\bullet$ & Define the potential risks, \\
& $\bullet$ & Lack on the organized laws, formal planning, and empirical frameworks, \\
& $\bullet$ & Include citizen participation to share the risks, \\
& $\bullet$ & Identify the gaps to prioritize investment opportunity. \\
\hline
\end{tabular}

Source: Summarized from $[22,23]$ \& by the author

\subsection{Infrastructure Implementation for Green Cities}

Development and establishment infrastructure are considered one of the major concerns in most countries, both developed and developing countries face huge challenges in implementing it, as the study mentioned above, and to merge the conventional and green infrastructure concepts in the development process is considered in itself an enormous challenge. Funding, technology, and high risks are the most important challenges in implementing both conventional and green infrastructure concepts.

Governments recognized that the bridge to overcome these challenges is the partnership with the private sector as a smart substitute to develop and expand the resource of infrastructural facilities [24]. The World Bank defines Public-Private Partnership (PPPs): "The partnership between the government and the private sector through cooperation between governmental entities such as local authorities and central governments with private companies in many areas such as health, education and infrastructure, and the degree of partnership varies in terms of responsibility and authority" [25]. In fact, Standard Public-Private Partnership (PPPs) agreements normally did not take social and environmental aspects in its consideration, thus, the term of green economic and green contracts must be appended in order to close this gap.

UNEP defines Green economy as "one that results in improved human well-being and social equity, while significantly reducing environmental risks and ecological scarcities. In its simplest expression, a green economy can be thought of as one which is a low carbon, resource-efficient and socially inclusive" [26].

From this point of view, the green economic strategies to accomplish green (PPPs) agreements are $[27,28]$ : 
- Reduce the consumption of natural resources, and investment in natural assets,

- Provide clean water and sanitation services, and efficient delivery for services,

- Reduce carbon emission,

- Reduce environmental risks,

- Dependent on renewable energy,

- Promote long term maintenance agreements for projects,

- Enable private sector to finance projects,

- Science, technology, and innovation (STI),

- Waste management through, reduce, Reuse and Recycle wastes from industry,

- Prevent the loss of biodiversity and ecosystem services.

As a result of the shift in (PPPs) strategies to promote the green economic term, that was reflected directly in the contractual relationship between parties to be green by involving environmental and social strategies in it. In this context, Sherpa defines the green contract as "all contracts which aim and execution conditions combine economic, environmental, and social aspects, to promote fundamental rights and environmental protection [29]." From this point, the green contract clauses must include:

- Apply Triple bottom line: people (social), planet and energy (environmental), and profit (economic),

- Organize a balance between economic, social, and environmental implications,

- Rise to obligations of prevention and compensation to social and environmental harm,

- Remedy the effects of the contract concerned on public interest considerations brought about by the research of sustainable development,

- Promote mechanisms to prevent disputes and damages,

- Achieve the balance of power between the contract's parties referring in particular to the idea of a sphere of influence,

- Encourage purchasing renewable energy or recycled materials,

- Reduce expenditure and waste; increase resource efficiency,

- A life cycle assessment of the environmental impacts (EIA) of products or services is required,

- Compare price, technology, quality, and the environmental impact of the product, service, or contract.

\section{Result}

\subsection{Conceptual Frame Work for Implementing Infrastructure Projects}

Based on the discussion and analysis for green city definition, infrastructure challenges, infrastructure implementation by (PPPs), green economic, and green contract in the literature review. That led the study to conclude the Operational Framework for implementing infrastructure projects by (PPPs) based on the green cities objectives as illustrated in Figure (1) below. The operational model's main objective is achieving "green infrastructure project through (PPPs)" as well as:

- Determining the main phases in (PPPs),

- Allocating the most important strategies for each phase,

- The main output from each stage,

- Indicating the main internal stockholders, who share in decision making for each phase.

\subsection{Efficiency Indicators for Green Infrastructure Projects}

In order to achieve the green cities approach, and to evaluate the operational framework outputs through the (PPPs) phases and track the achievement of it, the study assigns the indicators according to the following criteria: the indictors should reflect the features of the green city concept, the index should represent the sustainable three pillars (environmental, economic, social), and (PPPs) potential risks in the project phases. Using the above criteria, the study summarized (53) indicators, classified on (38) indicators related to the green city concept, and (15) related to the potential risks.

After selecting the indicators, an online questionnaire is prepared and evaluated by (15) experts specialized in environmental planning and project management to obtain a weight for each indicator by identifying the Relative Importance Index. The collected data were analyzed and concluded the Mean Value for Each Indicator using the Statistical Analysis Program (SPSS), then calculated the Relative Importance Index (RII) using (Likert) classification (k) as [30]: " 5 " extremely high, "4" high, "3" medium, " 2 " low, and " 1 " extremely low, and examined the results by the equation below:

$$
\begin{gathered}
\mathrm{RII}(\%)=n_{1}+2 n_{2}+3 n_{3}+4 n_{4}+5 n_{5} / 5\left(n_{1}+n_{2}+\right. \\
\left.n_{3}+n_{4}+n_{5}\right) * 100
\end{gathered}
$$

Where $n 1, n 2, n 3, n 4$, and $n 5$ are the numbers of the students who scored "1" extremely low, "2" low, "3" medium, "4" high, and " 5 " extremely high. Then the study set the Importance level as follow [31]:

- $\quad \mathrm{RII}=0: 0.20=$ Importance level $(\mathrm{Low}=\mathrm{L})$

- $\mathrm{RII}=0.21: 0.40=$ Importance level $($ Medium low $=$ M-L)

- $\mathrm{RII}=0.41: 0.60=$ Importance level $($ Medium $=\mathrm{M})$

- $\mathrm{RII}=0.61: 0.80=$ Importance level $($ Medium high $=$ $\mathrm{M}-\mathrm{H})$

- $\mathrm{RII}=0.81: 1.00=$ Importance level $($ High $=\mathrm{H})$

The results of the Questionnaire were summarized as shown in Table (4). 


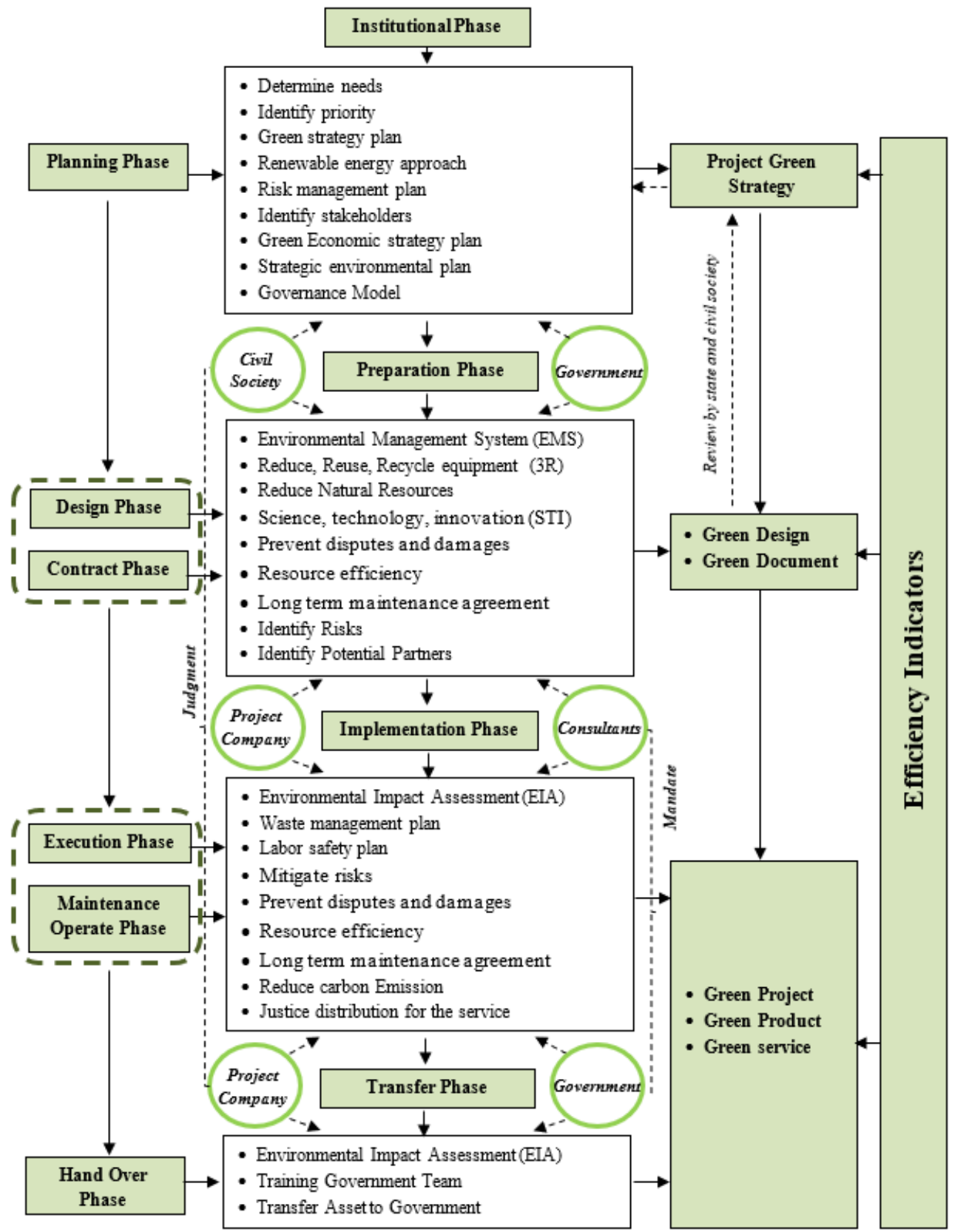

Source: by the author

Figure 1. Operational Framework for Green (PPPs) 
Table 4. Efficiency Indicators

\begin{tabular}{|c|c|c|c|c|c|c|}
\hline $\begin{array}{c}\text { Project } \\
\text { Phase }\end{array}$ & Classification & Efficiency Indicators & Mean & RII & $\begin{array}{c}\begin{array}{c}\text { Importance } \\
\text { level }\end{array} \\
\end{array}$ & $\begin{array}{l}\text { Relative } \\
\text { Ranking } \\
\end{array}$ \\
\hline \multirow{16}{*}{ 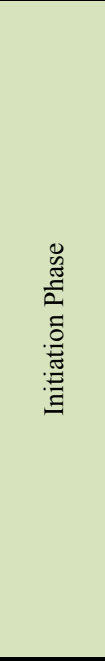 } & \multirow{6}{*}{ Environmental } & CO2 Reduction strategy & 4.174 & 0.849 & $\mathrm{H}$ & 5 \\
\hline & & Clean and efficient energy policy & 4.604 & 0.921 & $\mathrm{H}$ & 2 \\
\hline & & Congestion reduction policy & 4.143 & 0.798 & M_H & 9 \\
\hline & & Water efficiency and treatment policy & 4.563 & 0.910 & $\mathrm{H}$ & 3 \\
\hline & & Waste reduction policy & 4.665 & 0.931 & $\mathrm{H}$ & 1 \\
\hline & & Clear air policy & 4.542 & 0.910 & $\mathrm{H}$ & 3 \\
\hline & \multirow{3}{*}{ Economic } & Green economic strategy & 4.297 & 0.859 & $\mathrm{H}$ & 4 \\
\hline & & Green procurement policy & 4.532 & 0.910 & $\mathrm{H}$ & 3 \\
\hline & & (PPPs) policy & 4.194 & 0.839 & $\mathrm{H}$ & 7 \\
\hline & \multirow{3}{*}{ Social } & Civil society participation (NGOs) & 2.711 & 0.542 & M & 11 \\
\hline & & Governance policy & 4.245 & 0.849 & $\mathrm{H}$ & 6 \\
\hline & & Identifying actual priority & 4.614 & 0.921 & $\mathrm{H}$ & 2 \\
\hline & \multirow{4}{*}{ Potential Risks } & Poor public decision-making process & 2.302 & 0.460 & $\mathrm{M}$ & 12 \\
\hline & & Delay in project approval and permits & 4.583 & 0.921 & $\mathrm{H}$ & 2 \\
\hline & & Corruption and lack of law respect & 4.092 & 0.818 & M_H & 8 \\
\hline & & Changes in related laws & 3.908 & 0.777 & $\mathrm{M} \_\mathrm{H}$ & 10 \\
\hline \multirow{11}{*}{ 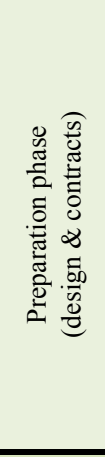 } & \multirow{4}{*}{ Environmental } & Environmental Management System (EMS) & 4.583 & 0.921 & $\mathrm{H}$ & 2 \\
\hline & & Expected Energy consumption & 4.358 & 0.870 & $\mathrm{H}$ & 4 \\
\hline & & Expected Natural Resources consumption & 4.859 & 0.972 & $\mathrm{H}$ & 1 \\
\hline & & Smart technology application & 4.348 & 0.870 & $\mathrm{H}$ & 4 \\
\hline & \multirow{2}{*}{ Economic } & Resource efficiency & 4.297 & 0.859 & $\mathrm{H}$ & 5 \\
\hline & & Cost efficiency (Benefit / Cost) & 4.542 & 0.910 & $\mathrm{H}$ & 3 \\
\hline & \multirow{2}{*}{ Social } & Civil society participation (NGOs) & 0.706 & 0.133 & $\mathrm{~L}$ & 9 \\
\hline & & Citizen interaction with the government & 3.826 & 0.767 & M_H & 8 \\
\hline & \multirow{3}{*}{ Potential Risks } & High finance cost & 4.194 & 0.839 & $\mathrm{H}$ & 6 \\
\hline & & Inflation rate & 3.887 & 0.777 & M_H & 7 \\
\hline & & Providing investors & 3.908 & 0.777 & $\mathrm{M} \_\mathrm{H}$ & 7 \\
\hline \multirow{21}{*}{ 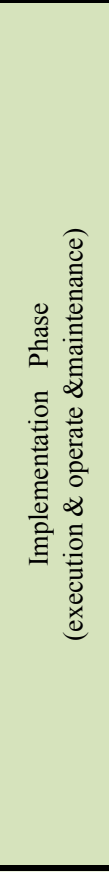 } & \multirow{10}{*}{ Environmental } & $\mathrm{CO} 2$ emission & 4.205 & 0.839 & $\mathrm{H}$ & 7 \\
\hline & & Energy consumption & 4.174 & 0.839 & $\mathrm{H}$ & 7 \\
\hline & & Renewable energy consumption & 4.491 & 0.900 & $\mathrm{H}$ & 4 \\
\hline & & Water consumption & 4.358 & 0.870 & $\mathrm{H}$ & 5 \\
\hline & & Water system leakage & 3.724 & 0.747 & M_H & 11 \\
\hline & & Waste water treatment & 4.614 & 0.921 & $\mathrm{H}$ & 2 \\
\hline & & Waste production & 4.143 & 0.798 & M_H & 9 \\
\hline & & Waste recycling & 2.916 & 0.583 & $\mathrm{M}$ & 12 \\
\hline & & Nitrogen dioxide & 4.532 & 0.910 & $\mathrm{H}$ & 3 \\
\hline & & Particulate matter & 2.465 & 0.491 & M & 14 \\
\hline & \multirow{2}{*}{ Economic } & Service tariff & 4.205 & 0.839 & $\mathrm{H}$ & 7 \\
\hline & & long term maintenance agreement & 4.818 & 0.962 & $\mathrm{H}$ & 1 \\
\hline & \multirow{3}{*}{ Social } & Stakeholder communication & 4.123 & 0.829 & $\mathrm{H}$ & 8 \\
\hline & & prevent disputes and damages & 4.307 & 0.859 & $\mathrm{H}$ & 6 \\
\hline & & Justice distribution for the service & 3.939 & 0.788 & M_H & 10 \\
\hline & \multirow{6}{*}{ Potential Risks } & Construction cost overruns & 3.979 & 0.798 & $\mathrm{M} \_\mathrm{H}$ & 9 \\
\hline & & Quality failure & 2.394 & 0.481 & M & 15 \\
\hline & & Construction time delay & 2.302 & 0.460 & $\mathrm{M}$ & 16 \\
\hline & & Change in market demand & 4.010 & 0.798 & M_H & 9 \\
\hline & & Maintenance quality & 2.834 & 0.563 & $\mathrm{M}$ & 13 \\
\hline & & Environmental Impact Assessment (EIA) & 4.552 & 0.910 & $\mathrm{H}$ & 3 \\
\hline \multirow{5}{*}{ 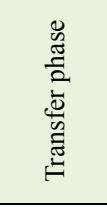 } & Environmental & Environmental Impact Assessment (EIA) & 4.297 & 0.859 & $\mathrm{H}$ & 3 \\
\hline & Economic & Overall profit for all stockholders & 4.092 & 0.818 & $\mathrm{M} \_\mathrm{H}$ & 4 \\
\hline & Social & Client satisfaction & 4.818 & 0.962 & $\mathrm{H}$ & 1 \\
\hline & \multirow{2}{*}{ Potential Risks } & Renewal risk & 4.491 & 0.900 & $\mathrm{H}$ & 2 \\
\hline & & Transfer asset to government & 2.55 & 0.51 & $\mathrm{M}$ & 5 \\
\hline
\end{tabular}




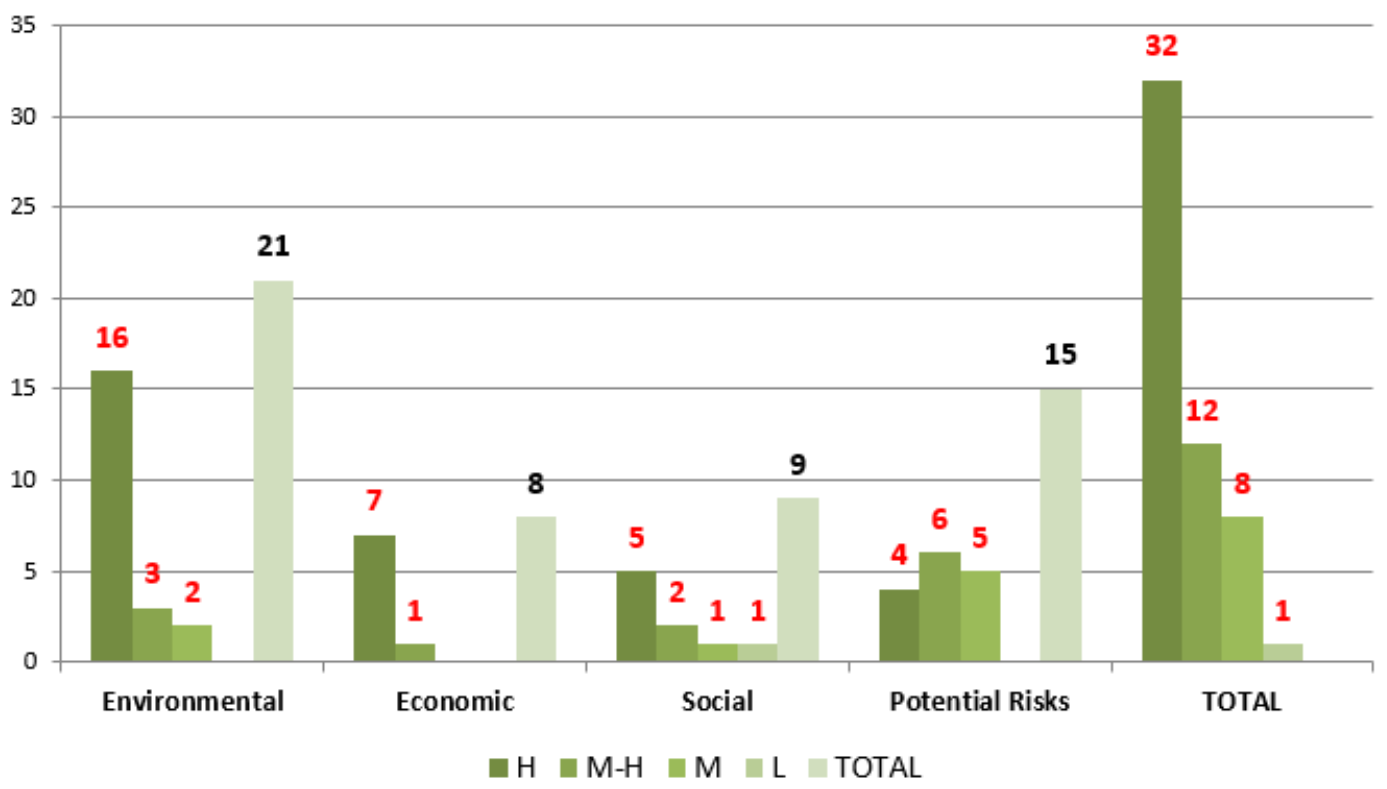

Source: by the author

Figure 2. The Importance Level for the Efficiency Indicators

\section{Analysis and Discussion}

Efficiency indicators were distributed according to the infrastructure projects phases, each phase was included indicators reflecting the 3 pillars of sustainability and the potential risks related to this phase. The overall indicators for all categories were (53), (32) indicators ranked high importance $(\mathrm{H})$, (12) indicators ranked medium-high (M-H), (8) indicators ranked medium (M), and (1) indicator ranked low (L). The distribution of the ranks for the 3 pillars and the potential risks was illustrated in Figure (2).

- Regarding Initiation Phase: the total efficiency indicators for this phase were (16), the most important indicator related to the relative ranking for this phase is Waste reduction policy, and it was distributed as: (6) for environmental pillar, (3) for economical pillar, (3) for social pillar, and (4) for potential risks as illustrated in Figure (2). The expert's evaluation range was $(\mathrm{H})$ for $(11)$ indicators, $(\mathrm{M}-\mathrm{H})$ for (3) indicators, and (M) for (2) indicators. That reflects the importance of this phase where (14) indicator's range was between $(\mathrm{H})$ and $(\mathrm{M}-\mathrm{H})$ which represents $(87.5 \%)$ from the phase indicators, therefore, identifying the sustainable strategies and policies is essential in this phase, also, the stability in laws and the acceleration of administrative procedures for the project by the government are considered critical issue in this phase.

- Regarding Preparation Phase: the total efficiency indicators for this phase were (11), the most important indicator related to the relative ranking for this phase is Expected Natural Resources consumption, and it was distributed as: (4) for environmental pillar, (2) for economical pillar, (2) for social pillar, and (3) for potential risks. The expert's evaluation range was $(\mathrm{H})$ for (7) indicators, (M-H) for (3) indicators, and (L) for (1) indicators. In fact, all the environmental indicators' ranks were $(\mathrm{H})$, which reflects the importance of the environmental role in this phase, therefore, including it as parameters in the design process and in the signed agreements with the private partner is too important to achieve green cities concept. Particularly, the expected natural recourses consumption and dependent on smart technologies.

Regarding Implementation Phase: the total efficiency indicators for this phase were (21), the most important indicator related to the relative ranking for this phase is long term maintenance agreement, and it was distributed as: (10) for environmental pillar, (2) for economical pillar, (3) for social pillar, and (6) for potential risks. The expert's evaluation range was $(\mathrm{H})$ for (11) indicators, (M-H) for (5) indicators, and (M) for (5) indicators. As a result of the nature of this phase that considers the longest phase of the project lifecycle because it includes execution, operation, and maintenance agreements, it acquires (39.6\%) from the efficiency indicators. Application of the environment role by assessing all the environmental aspects during this phase is crucial, especially co2 emission, energy and water consumption. Any defect in the result of these indicators is considered a failure for the project, therefore, environmental impact assessment (EIA) in this phase was a high potential risk.

- Regarding Transfer Phase: the total efficiency indicators for this phase were (5), the most important indicator related to the relative ranking for this phase is Client satisfaction, and it was distributed as: (1) for environmental pillar, (1) for economical pillar, (1) for 
social pillar, and (2) for potential risks. The experts' evaluation range was $(\mathrm{H})$ for $(3)$ indicators, $(\mathrm{M}-\mathrm{H})$ for (1) indicators, and (M) for (1) indicators. This phase is the final phase in the project lifecycle, if the implementation phase achieves its goals that means a safe transfer for the asset to the government in a good condition, and arriving to the customer satisfaction.

\section{Conclusions}

Green city is an important concept to achieve sustainable development pillars, it is not only green urban spaces or green building but also expands to green economic and social aspects, many strategies were adopted to achieve this concept, the most important strategies related to this concept are reducing the natural resources consumption, reusing and recycling water and waste, and promoting the use of smart technologies. Infrastructure development considers the main pivot for achieving this concept, where, the development in this sector reflects communities' growth and welfare, from another hand, the implementation of this concept faces numerous challenges particularly in funding, providing technology, and the high potential risks. The green Public-Private partnership (PPPs) approach is the gate to overcome these challenges through green economy, green agreements, improve communication between stakeholders, and encourage civil society participation in decision making.

Finally, the suggested operational framework and efficiency indicators for green infrastructure could enhance the implementation of the green city concept through reducing the gap between theory and practice, mitigating the potential risks, and identifying the sustainable strategies and policies thus, achieving sustainable development.

\section{REFERENCES}

[1] United Nations, "Transforming our world: the 2030 Agenda for Sustainable Development”, pp. 14, 2015.

[2] N. Bagheri. "The Built Environment in the Critical Zone: From Pre- to Postindustrial Cities. science direct”, 2015.

[3] B. Ogenis, K. Jannes. "Green City Concept and a Method to Measure Green City Performance over Time Applied to Fifty Cities Globally: Influence of GDP, Population Size and Energy Efficiency", Sustainability, v.10, issue 6, June 2018, DOI10.3390/su10062031.

[4] Lindfield, Michael and S. Florian. "Spatial Development and Technologies for Green Cities" in urban development series; Green Cities., Asian Development Bank, Philippines, 2012 .

[5] Asian Development Bank (ADB). Green City Development
Tool Kit; Asian Development Bank: Manilla, Philippines, 2015.

[6] City Green: "Innovative Green Infrastructure Solutions for Downtowns and Infill Locations", EPA, United States Environmental; Protection Agency, EPA 230R16001, May 2016. www.epa.gov/smartgrowth

[7] UN Habitat. Habitat III Issue Papers on Urban and Spatial Planning and Design; UN Habitat: New York, NY, USA, 2015.

[8] Z. Tomor, A. Meijer, A. Michels, S. Geertman. "Smart Governance for Sustainable Cities: Findings from a Systematic Literature Review", Journal of Urban Technology, Informa UK Limited, trading as Taylor \& Francis, VOL. 26, NO. 4, pp. 3-27, 2019.

[9] Uraía Workshop. "Public-Private Partnerships for Smart City Management”, Oslo, June 2015.

[10] Asian Development Bank (ADB). Green City Development Tool Kit; Asian Development Bank: Manilla, Philippines, 2015.

[11] World Bank. "Benchmarking Public-Private Partnerships Procurement 2017: Assessing Government Capability to Prepare, Procure, and Manage PPPs." Washington, DC, 2016.

[12] P. A. Pykhov, T. O.Kashina. "Infrastruktura kak objekt ekonomicheskix issledovanij [Infrastructure as an object of economic research]". Zhurnal ekonomicheskoy teorii Russian Journal of Economic Theory, No. 1, pp. 39-46, 2016.

[13] G. M. Vaughan. Strategic Infrastructure. Steps to Prioritize and Deliver Infrastructure Effectively and Efficiently. World Economic Forum Report, 2012. Available at: http://www3.weforum.org/docs/WEF IU StrategicInfrastru cture_Report_2012.

[14] E. Christopher. Green Infrastructure: Sustainable Solutions in 11 Cities across the United States, Columbia University Water Center, ISTAT, 2006.

[15] E. Christopher. Green Infrastructure: Sustainable Solutions in 11 Cities across the United States, Columbia University Water Center, ISTAT, P.16, 2014.

[16] L. Emily. NYC Green Infrastructure, Annual Report, 2013.

[17] M. gabriela. Green cities - Urban planning models of the future. Turkey: Research gate, 2014.

[18] A. Mark, Ph. D. Benedict, T. Edward, J. D. McMahon. "Green Infrastructure: Smart Conservation for the 21st Century", Sprawl Watch Clearinghouse, Washington, D.C. 20036, 202-332-7000, www.sprawlwatch.org

[19] United Nations Commission on Science and Technology for Development UNCTAD. "Smart Cities and Infrastructure. Inter-Sessional Panel. Budapest". Hungary, 2016.

[20] A. V. Gheorghe, D. V. Vamanu, P. F. Katina, R, Pulfer. "Critical Infrastructures, Key Resources, and Key Assets, Cham, Switzerland: Springer International Publishing, 2018.

[21] United Nations Commission on Science and Technology 
for Development UNCTAD." Smart Cities and Infrastructure", Inter-Sessional Panel, Budapest, Hungary, (EU), $\quad$ pp.15-27, January 2016. https://unctad.org/meetings/en/SessionalDoc uments/CSTD_2015_Issuespaper_Theme1_SmartCitiesand Infra_en.pdf ( $\overline{\text { Accessed }} 27$ March 2020$)$.

[22] H. Christine, K. Cecil. "Challenges and strategies for urban green-space planning in cities undergoing densification: A review" Urban Forestry \& Urban Greening, V. 14, (2015), DOI: 10.1016/j.ufug.2015.07.009.

[23] S. Paulina, M. Bernhard. "Planning Green Infrastructure as a Source of Urban and Regional Resilience - Towards Institutional Challenges" Urbani Izziv, November 2015, DOI: 10.5379/urbani-izziv-en-2015-26-supplement-00.

[24] W. Kenton. "Public-Private Partnerships", 2019, Retrieved 9 May 2020, fromhttps://www.investopedia.com/terms/p/pub lic-private-partnerships.asp

[25] World Bank. "Benchmarking Public-Private Partnerships Procurement 2017": Assessing Government Capability to Prepare, Procure, and Manage PPPs." Washington, DC, 2016.

https://ppp.worldbank.org/public-private-partnership/sites/p pp.worldbank.org

[26] UNEP, "Towards a Green Economy: Pathways to Sustainable Development and Poverty Eradication - A Synthesis for Policy Makers", 2011, https://sustainabledeve lopment.un.org/content/documents/126GER_synthesis_en

[27] UNDESA. "Green Economy, Green Growth, and Low-Carbon Development - history, definitions and a guide to recent publications Division for Sustainable Development", A guidebook to the Green Economy, August 2012.

[28] M. Leonardo, T. B. Patrick, F. Doreen. "Green Economy;
Supporting Briefing Green Economy in The European Union” UNEP, May 2012.

[29] Q. Yann, “Sustainable Contracts; Concept's outlines and exploration tracks", P. 2:5, January 2010.

[30] Ankur Joshi, S. K., Likert Scale: Explored and Explained. British Journal of Applied Science \& Technology. 2015, doi:10.9734/BJAST/2015/14975

[31] K. Hatkar, N. Hedaoo. "Dely Analysis by Using Relative Importance Index Method in Infrastructure Projects". International Journal of Civil Engineering and Concrete Strutures, Vol. 1, No. 3, October 2016.

[32] M. Muya, Ch. Kaluba, I. N. Banda, S. Rattray, Ch. Mubemba, G. Mukelabai, "Infrastructure Watch Culture: Zambia's Infrastructure Report Card", Civil Engineering and Architecture, v. 5, issue 1, pp. 8-17, 2017, DOI: 10.13189/cea.2017.050102, http://www.hrpub.org.

[33] Keçi. Julinda. "Public Private Partnership for Infrastructure Projects: Mapping the Key Risks". International Journal of Social, Behavioral, Educational, Economic, Business and Industrial Engineering, Vol. 9, No. 9, 2015.

[34] H. Sarvari, A. Valipour, N. Yahaya, M. N. Norhazilan. "Risk Ranking of Malaysian Public Private Partnership Projects". Applied Mechanics and Materials, Volume 567, pp. 613-618, 2014.

[35] Siemens AG. "European Green City Index; Assessing the environmental impact of Europe's major cities", Munich, Germany, 2009.

[36] B. Ogenis, K. Jannes. "Green City Concept and a Method to Measure Green City Performance over Time Applied to Fifty Cities Globally: Influence of GDP, Population Size and Energy Efficiency", Sustainability, v.10, issue 6, June 2018, DOI10.3390/su10062031. 